\title{
Neurocognitive dysfunction among HIV positive patients using International HIV dementia scale
}

\author{
Basavaprabhu Achappa', Shivani Priyadarshni², Deepak Madi ${ }^{3}$, Unnikrishnan Bhaskaran ${ }^{4}$, \\ John T Ramapuram ${ }^{5}$, Satish Rao ${ }^{6}$, Mukta Chowta ${ }^{7}$, Soundarya Mahalingam ${ }^{8}$
}

${ }^{1}$ Associate Professor, Department of Internal Medicine, Kasturba Medical College, Mangalore (affiliated to Manipal University), ${ }^{2}$ Final Year MBBS Student, Kasturba Medical College, Mangalore (affiliated to Manipal University), ${ }^{3}$ Associate Professor, Department of Internal Medicine, Kasturba Medical College, Mangalore (affiliated to Manipal University), ${ }^{4}$ Professor \& HOD, Department of Community Medicine, Kasturba Medical College, Mangalore (affiliated to Manipal University), ${ }^{5}$ Professor, Department of Internal Medicine, Kasturba Medical College, Mangalore (affiliated to Manipal University), ${ }^{6}$ Additional Professor, Department of Internal Medicine, Kasturba Medical College, Mangalore (affiliated to Manipal University), ${ }^{7}$ Additional Professor, Department of Pharmacology, Kasturba Medical College, Mangalore (affiliated to Manipal University), ${ }^{8}$ Associate Professor, Department of Paediatrics, Kasturba Medical College, Mangalore (affiliated to Manipal University)

\section{A B S T R A C T}

Background: HIV associated neurocognitive dysfunction (HAND) ranges from asymptomatic neurocognitive impairment (ANI) to mild neurocognitive disorders (MND) to HIV associated dementia (HAD). Cognitive impairment may impact medication adherence which will ultimately affect morbidity and mortality. Aim: This study was undertaken to evaluate neurocognitive dysfunction among HIV positive patients using the International HIV Dementia scale(IHDS). Materials and Methods: This cross sectional study was conducted in a tertiary care hospital attached to a medical college that caters to a large number of HIV positive patients. The subjects for this study included HIV positive patients belonging to WHO stage 1 or 2. Data collection was done using a pre tested questionnaire. The International HIV Dementia scale(IHDS) was used to assess HAND. Results: Out of the 101 patients studied, 69(68.3\%) were males and 32(31.7\%) were females. Among these patients, $88(87.1 \%)$ were receiving antiretroviral therapy (ART), $84(83.2 \%)$ were in WHO stage 1. $91(90.1 \%)$ patients had HAND. There were statistically significant differences in the gender and educational level between patients with or without HAND. As age advanced the percentage of patients having HAND also increased. Conclusion: There was high prevalence of HIV associated neurocognitive dysfunction among HIV positive individuals in our study. Also there was an increase in HIV associated neurocognitive dysfunction with increase in age.

Key words: HIV, HIV associated neurocognitive dysfunction (HAND), HIV dementia
Access this article online

Website:

http://nepjol.info/index.php/AJMS

\section{INTRODUCTION}

A variety of neurocognitive disorders may develop in HIV patients. These HIV associated neurocognitive dysfunction (HAND) ranges from asymptomatic neurocognitive impairment(ANI) to mild neurocognitive disorders (MND) to HIV associated dementia. ${ }^{1}$ The most severe form of impairment is HIV-associated dementia. With antiretroviral treatment, the frequency of dementia hasdecreased, but milder forms of impairment remain highly prevalent and increase with age. ${ }^{2}$

With increase in age of HIV positive population due to antiretroviral therapy, prevalence of cognitive disordersis likely to be higher among older HIV positive patients. HANDmay become the most common cause of dementia in the future. Studies conducted in HIV patients estimate that the prevalence of neurocognitive dysfunction (based on neuropsychological assessments) ranges from $20-37 \%$, even with treatment. ${ }^{3}$

Cognitive impairment may impact medication adherence which will ultimately affect morbidity and mortality. Hence it is important to detect it early and follow effective strategy to improve adherence in these patients. Cognitive impairment may also affect workplace functioning of HIV patients. ${ }^{4}$ Various neuropsychological tests can be used to diagnose HAND. However, administration of the entire 
neuropsychological test battery is difficult in routine clinical practice because it is time-consuming and needs manpower. The International HIV Dementia Scale (IHDS) ${ }^{5}$ is a rapid screening test that can be used in an outpatient setting to screen asymptomatic HIV patients for HAND. Very few studies have been published from India that have used IHDS scale to assess HAND in HIV patients. Hence this study was undertaken to evaluate neurocognitive disorder among asymptomatic HIV patients.

\section{MATERIALS AND METHODS}

The study was approved by institutional ethics committee of Kasturba Medical College, Mangalore.

\section{Study population, study design and setting}

A facility based cross-sectional study was carried out among 101 People Living with HIV (PLHIV). The study was carried out at Kasturba Medical College hospital (tertiary health care centre) in Mangalore (South India).

Sample size was calculated based on expected proportion of neurocognitive impairment among HIV patients as $38 \%$ based on previous studies ${ }^{6}$ with precision of $10 \%$ and confidence interval of $95 \%$ and $80 \%$ power, the minimum sample size was 91 . Taking non response error as $10 \%$ the final sample size was 101. Sampling method was by convenient sampling.

Inclusion criteria were: documented HIV-positive status(diagnosed at Integrated Counseling and Testing Centre (ICTC)),age 18-60 years, ambulatory patients and patients who gave written informed consent. Exclusion criteria were patients who had central nervous system opportunistic infections, history of head injury,current opportunistic infection, history of psychiatric disorder and history of substance abuse. The study population for this analysis included HIV positive individuals (currently WHO stage 1 or 2).

Demographic data, medical history and physical examination were documented using a pretested proforma. CD4 count result was extractedfrom case records. Neuropsychological testing was conducted using the International HIV Dementia scale(IHDS). ${ }^{5}$ IHDS consists of 3 subsets: timed finger tapping (measures motor speed), timed alternating hand sequence test (measures psychomotor speed) and recall of 4 items in 2 minutes (assesses memory registration and recall). Each of these subtests is rated on a scale of $0-4$. The cut-off value for defining cognitive impairment was 10 .

\section{Statistical analysis}

Data collected was analyzed using SPSS Version 11.5. Student' $t$ ' test was used to analyze the quantitative data and chi square test was done to analyze qualitative data. A ' $\mathrm{p}$ ' value less than 0.05 was taken as statistically significant.

\section{RESULTS}

Out of the 101 patients studied, 69(68.3\%) were males and $32(31.7 \%)$ were females. Among these patients, $88(87.1 \%)$ were receiving antiretroviral therapy (ART).84 (83.2\%) patients were in WHO stage 1 and 17(16.8\%) were in WHO stage $2.91(90.1 \%)$ patients had HAND and the remaining $10(9.9 \%)$ did not have HAND (Table 1$)$.

Comparison of baseline characteristics showed statistically significant differences in the baseline $\mathrm{CD}_{4}$ count, gender and educational level between patients with or without HAND ( $\mathrm{p}=0.02, \mathrm{p}=0.006, \mathrm{p}=0.03$ respectively) (Table 1$)$.

Table 2 shows the distribution of patients with or without HAND based on age. As the age advances, percentage of patients having HAND also increased. Below 40 years of age group, $82.9 \%$ developed HAND whereas in age group of above 40 years HAND was observed in $95 \%$ of patients.

As shown in Table 3, there were differences between those with normal cognition and those with HAND for IHDS total score and for IHDS component score.

\section{DISCUSSION}

The present study was undertaken to evaluate neurocognitive dysfunction in HIV patients using IHDS. In our study among 101 patients, 91 had HAND. We used IHDS to assess neurocognitive dysfunctionin our study. The IHDS does not require patients to be proficient in English, can be performed in 3-5 minutes in an outpatient setting and requires no specialinstruments. ${ }^{7}$

Prevalence of cognitive impairment differs substantially among studies owing to different methodological approaches and study populations. In a study done in Tamil nadu, out of 33 patients 21 (63\%)patients had a score less than 10 using the IHDS scale. ${ }^{8}$ Chan LG et al have mentioned that that one in five HIV-positive patientsfrom a South Asian population can be expected to haveHAND. Robertson $\mathrm{K}$ et $a l^{10}$ reported that the prevalence of HAND is approximately $37 \%$. In a study done by Oshinaike OO et al in $250 \mathrm{HIV}$ patients, $34.4 \%$ had clinically evident neurological disease out of which 53\% had HAND. ${ }^{11}$ Oshinaike OO et al. ${ }^{12}$ haveused the IHDS scale(cutoff score of 10) to identify HAND among 208 HIV patients. In their study 113 patients (54.3\%) had HAND. In a study done by Atashili et al.85\% of subjects screened positive for dementia ( $\leq 10$ on IHDS). ${ }^{13}$ Similar results $(80 \%)$ were 


\begin{tabular}{|c|c|c|c|c|}
\hline Baseline characteristics & Total $(n=101)$ & Patients with HAND ( $n=91)$ & Patients without HAND $(n=10)$ & $p$ value \\
\hline Age in years (mean $\pm S D)$ & $42.81 \pm 9.32$ & $43.40 \pm 9.02$ & $37.50 \pm 10.84$ & 0.06 \\
\hline \multicolumn{5}{|l|}{ Gender n (\%) } \\
\hline Male & $69(68.3)$ & $66(72.5)$ & $3(30)$ & \multirow[t]{2}{*}{0.006} \\
\hline Female & $32(31.7)$ & $25(27.5)$ & $7(70)$ & \\
\hline \multicolumn{5}{|l|}{ Educational level n (\%) } \\
\hline Illiterate & $30(29.7)$ & $30(33)$ & $0(0)$ & \multirow[t]{4}{*}{0.03} \\
\hline Primary & $26(25.7)$ & $21(23.1)$ & $5(50)$ & \\
\hline Secondary & $30(29.7)$ & $27(29.7)$ & $3(30)$ & \\
\hline >Secondary & $15(14.9)$ & $13(14.2)$ & $2(20)$ & \\
\hline $\begin{array}{l}\text { Duration of HIV infection in } \\
\text { years (mean } \pm S D \text { ) }\end{array}$ & $5.54 \pm 4.8$ & $5.5407 \pm 4.86$ & $5.5550 \pm 4.45$ & 0.99 \\
\hline Baseline CD4 count cells/ $\mu \mathrm{L}$ (mean $\pm \mathrm{SD}$ ) & $237.48 \pm 207.13$ & $220.96 \pm 193.09$ & $384.33 \pm 277.09$ & 0.02 \\
\hline Current CD4 count cells/ $\mu \mathrm{L}$ (mean $\pm S D)$ & $450.9 \pm 283.49$ & $434.54 \pm 286.12$ & $599.80 \pm 216.73$ & 0.08 \\
\hline \multicolumn{5}{|l|}{ Receiving ART n (\%) } \\
\hline Yes & $88(87.1)$ & $81(92)$ & $7(8)$ & \multirow[t]{2}{*}{0.12} \\
\hline No & $13(12.9)$ & $10(76.1)$ & $3(23.9)$ & \\
\hline \multicolumn{5}{|l|}{ WHO stage $n(\%)$} \\
\hline 1 & $84(83.2)$ & $75(89.3)$ & $9(10.7)$ & \multirow[t]{2}{*}{0.87} \\
\hline 2 & $17(16.8)$ & $16(94.1)$ & $1(5.9)$ & \\
\hline
\end{tabular}

\begin{tabular}{lccc}
\multicolumn{4}{l}{ Table 2: Distribution of patients based on age } \\
group stratified by cognitive diagnosis \\
\hline Age group & $\begin{array}{c}\text { Patients with } \\
\text { HAND } \mathbf{n}(\%)\end{array}$ & $\begin{array}{c}\text { Patients without } \\
\text { HAND } \mathbf{n}(\%)\end{array}$ & p value \\
\hline$\leq 40$ years $(n=41)$ & $34(82.9 \%)$ & $7(17.1 \%)$ & 0.09 \\
$>40$ years $(n=60)$ & $57(95 \%)$ & $3(5 \%)$ & \\
\hline
\end{tabular}

\begin{tabular}{lcccc}
$\begin{array}{l}\text { Table 3: IHDS score stratified by cognitive } \\
\text { diagnosis }(\mathbf{n}=101)\end{array}$ & $\begin{array}{c}\text { All } \\
\text { patients }\end{array}$ & $\begin{array}{c}\text { Patients } \\
\text { with } \\
\text { HAND }\end{array}$ & $\begin{array}{c}\text { Patients } \\
\text { without } \\
\text { HAND }\end{array}$ & p value \\
\hline IHDS score & $10.9 \pm 0.46$ & $8.78 \pm 1.06$ & $10.90 \pm 0.46$ & 0.001 \\
\hline $\begin{array}{l}\text { Total score } \\
\text { Motor speed }\end{array}$ & $2.8 \pm 0.63$ & $2.73 \pm 0.6$ & $3.50 \pm 0.53$ & 0.001 \\
$\begin{array}{l}\text { Psychomotor } \\
\text { speed }\end{array}$ & $2.76 \pm 0.72$ & $2.67 \pm 0.68$ & $3.60 \pm 0.52$ & 0.001 \\
Memory recall & $3.44 \pm 0.71$ & $3.396 \pm 0.73$ & $3.800 \pm 0.0 .26$ & 0.09 \\
\hline
\end{tabular}

seen in a study done by Robbins et al. in South Africa. ${ }^{14}$ The prevalence of ANI/MND ranges from 26 to $76 \%$ and that of HIV-associated dementia (HAD) from 1-35\%. ${ }^{15}$

In our study the screen rate for HAND was high. We strongly suspect that the prevalence of HAND in Indian population is high as many patients present with advanced disease with low CD4 cell counts. Atashili et al. have mentioned that high screen positive rate could also be due to the IHDS performing poorly. They feel that antiretroviral drugs can reduce psychomotor speed and hence affect IHDS scale.

Risk factors for HAND are low CD4 cell counts, anemia, low body mass index, increasing age, and female gender. ${ }^{16-18}$ Chan LG et $a l^{9}$ have mentioned that patients with HAND tend to be older, have less education and low baseline CD4 counts (CD $4<200$ cells $/ \mathrm{ml})$. The mean age in the present study was found to be higher in HAND group(43.4 years) as compared to normal cognition group(37.5 years). Comparison of baseline characteristics showed statistically significant differences in the baseline $\mathrm{CD}_{4}$ count between patients with or without HAND.

Our study had some limitations. Our sample was predominantly urban. We did not use gold standard neuropsychological tests to confirm HAND in our study. But our main intention was to screen HIV patients for HAND using a simple and rapid screening tool.

To conclude, there was high prevalence of HANDamong HIV positive individuals in our study. Routine screening for HAND must be done by physicians involved in HIV care. IHDS is a simple screening tool which can be used to assess HAND even in an outpatient setting. More studies using IHDS scale should be done in our country. Failure to identify cognitive deficits may affect successful management of the disease.

\section{REFERENCES}

1. Antinori A, Arendt G, Becker JT, Brew BJ, Byrd DA, Cherner $M$, et al. Updated research nosology for HIV-associated neurocognitive disorders. Neurology 2007;69:1789-1799.

2. Heaton RK, Clifford DB, Franklin DR Jr, Woods SP, Ake C, Vaida F, et al.; CHARTER Group. HIV-associated neurocognitive disorders persist in the era of potent antiretroviral therapy: CHARTER Study. Neurology 2010;75:2087-2096.

3. Anand P, Springer SA, Copenhaver MM and Altice FL. Neurocognitive Impairment and HIV Risk Factors: A Reciprocal Relationship. AIDS Behav 2010;14:1213-1226.

4. Clifford DB and Ances BM. HIV-associated neurocognitive disorder. Lancet Infect Dis. 2013; 13(11):976-986. 
5. Sacktor NC, Wong M, Nakasujja N, Skolasky RL, Selnes OA, Musisi S, et al. International HIV Dementia Scale: a new rapid screening test for HIV dementia. AIDS 2005;19:1367-1374.

6. Lawler K, Mosepele M, Ratcliffe S, Seloilwe E, Steele K, NthobatsangR,et al. Neurocognitive impairment among HIVpositive individuals in Botswana: a pilot study. J Int AIDS Soc 2010;13:15.

7. Singh D, Sunpath H, John S, Eastham L and Gouden R. The utility of a rapid screening tool for depression and HIV dementia amongst patients with low CD4 counts- a preliminary report. Afr J Psychiatry (Johannesbg) 2008;11:282-286.

8. Muniyandi $\mathrm{K}$, Venkatesan $\mathrm{J}$, Arutselvi $\mathrm{T}$ and Jayaseelan $\mathrm{V}$. Study to assess the prevalence, nature and extent of cognitive impairment in people living with AIDS. Indian J Psychiatry 2012;54:149-153.

9. Chan LG, Kandiah N and Chua A. HIV associated neurocognitive disorders(HAND) in a South Asian population- contextual application of the 2007 criteria. BMJ Open 2012 13; 2:e000662.

10. Robertson K, Liner $\mathrm{J}$ and Heaton R. Neuropsychological Assessment of HIV infected Population in International Settings. Neuropsychol Rev 2009;19:232-249.

11. Oshinaike OO, Okubadejo NU, Ojini FI and Danesi MA. The clinical spectrum of neurological manifestation in HIVIAIDS patients on HAART at the Lagos University Teaching Hospital, Lagos, Nigeria. Nig Q J Hosp Med 2009;19:181-185.

12. Oshinaike OO, Akinbami AA, Ojo OO, Ojini IF, Okubadejo UN and Danesi AM. Comparison of the Minimental State Examination Scale and the International HIV Dementia Scale in Assessing
Cognitive Function in Nigerian HIV Patients on Antiretroviral Therapy. AIDS Res Treat 2012; 2012:581531.

13. Atashili J, Gaynes B N, Pence B W, Tayong G, Kats D, O'donnell $\mathrm{J} \mathrm{K}$,et al. Prevalence, characteristics and correlates of a positive-dementia screen in patients on antiretroviral therapy in Bamenda, Cameroon: a cross-sectional study. BMC Neurol 2013;13:86.

14. Robbins RN, Remien RH, Mellins CA, Joska JA and Stein DJ. Screening for HIV-Associated Dementia in South Africa: Potentials and Pitfalls of Task-Shifting. AIDS Patient Care STDS. 2011;13:587-593.

15. Meyer AC, Boscardin WJ, Kwasa JK and Price RW. Is It Time to Rethink How Neuropsychological Tests Are Used to Diagnose Mild Forms of HIV-Associated Neurocognitive Disorders? Impact of False-Positive Rates on Prevalence and Power. Neuroepidemiology 2013; 41(3-4):208-216.

16. Janssen RS, Nwanyanwu OC, Selik RM and Stehr-Green JK. Epidemiology of human immunodeficiency virus encephalopathy in the United States. Neurology1992;42:1472-1476.

17. McArthur JC, Hoover DR, Bacellar H, Miller EN, Cohen BA, Becker JT, et al. Dementia in AIDS patients: incidence and risk factors. Multicenter AIDS Cohort Study. Neurology 1993;43:2245-2252.

18. Chiesi A, Seeber AC, Dally LG, Floridia M, Rezza G and Vella S. AIDS dementia complex in the Italian National AIDS Registry: temporal trends (1987-93) and differential incidence according to mode of transmission of HIV-1 infection. J Neurol Sci 1996; 144:107-113.

\footnotetext{
Authors Contribution:

BA - The treating physician, Concept and Design of the study, analysis and interpretation, manuscript preparation, revision of the manuscript and literature search; DM - The treating physician, analysis and interpretation, manuscript preparation, revision of the manuscript and literature search; JTR, SR - The treating physicians, Concept and design; SP - data collection; UB - analysis and interpretation, manuscript preparation, statistical analysis; MC, SM - Proof reading, editing and revision of manuscript.
}

Source of Support: ICMR-STS PROJECT REFERENCE ID: 2012-00148, Conflict of Interest: None declared. 